\title{
XXIV. On the determination of chemical affinity in terms of electromotive force.-Part III
}

\section{C.R. Alder Wright D.Sc.}

To cite this article: C.R. Alder Wright D.Sc. (1881) XXIV. On the determination of chemical affinity in terms of electromotive force.-Part III, Philosophical Magazine Series 5, 11:67, 169-196, DOI: $10.1080 / 14786448108626994$

To link to this article: http://dx.doi.org/10.1080/14786448108626994

册 Published online: 24 Aug 2010.

Submit your article to this journal $₫$

Џll Article views: 4

Q View related articles $\square$ 
in the shining rectangle, just above the theoretical limit of the prismatic spectrum, given by many phosphorescent substances.

University of New York, Dec. $1,1880$.

XXIV. On the Determination of Chemical Affinity in terms of Electromotive Force.-Part III.* By C. R. AlDER WRIGHT, D.Se. (Lond.), Lecturer on Chemistry and Physics in St. Mary's Hospital Medical School†.

On the Absolute Values of the Ohn and of the Mechanical Equivalent of Heat, and on the Nature of Polarization and Electrolysis, and the amount of work done when the latter occurs.

55. SINCE the publication of Parts I. and II. of these $D$ researches, it has been obligingly pointed out by Mr. L. B. Fletcher, of Baltimore (Phil. Mag. [5] x. p. 436), that, by a slip, it is stated in $\S 35$ that the values of the B.A. unit of resistance deducible from the 1867 experiments of Joule and from those detailed in Part II., are from 1.5 to $2 \cdot 0$ per cent. above one earth-quadrant per second, instead of that amount below this theoretical value, it being assumed that the mean water-friction value of Joule (41.555 megalergs, $\$ 34$ ) is correct; and $\mathrm{Mr}$. Fletcher also states that the first results of an experimental redetermination of the absolute value of the ohm, on which he is now engaged, are similar in character. Besides the valuations of Lorenz and Kohlrausch, briefly referred to in Part $I$. as illustrations of the want of absolute certainty as to the true value of the B.A. unit, two other sets of observations on this point have been made within the last two or three years-one by Prof. H. A. Rowland (Silliman's Journal [3] Xv. pp. 281, 325, and 430, 1878), and the other by H. F. Weber (Phil. Mag. [5] v. pp. 30, 127, and 189, 1878). By making observations of the value of the current induced in one coil by the establishment of a measured current in another one, Rowland obtained values of the resistance of the former such that, by comparison with four copies of the B.A. unit (or a multiple thereof), the following numbers were obtained as the resistance of the latter:-

* Part I., Proceedings of the Physical Society, 1880, vol. iii. p. 213; also Phil. Mag. April 1880. Part II., Proc. Phys. Soc. 1880, vol. iii. p. 246; also Phil. Mag. May 1880.

$\uparrow$ Communicated by the Physical Society. 
Coil No. 1. B.A. unit, by Elliot . . . 0.99257

Earth-quadrant per second.

$$
\begin{aligned}
& \text { "2. 10-ohm coil, " . . . 0.98963 } \\
& \text { "3. 10-ohm coil, by Warden, Mur- } \\
& \text { " 4. } 100 \\
& \text { head, and Clark . . . }\} 0.99129
\end{aligned}
$$

Hence, on the whole, Rowland's experiment indicates an error in the B.A. unit of $0.00888=0.888$ per cent. in deficiency.

Weber's determinations, on the other hand, indicate that the B.A. unit is nearly correct, the slight error being one of excess, and that the value of $\mathrm{J}$ is somewhat above that deduced from Joule's water-friction experiments. Thus he obtained the following values for $\mathbf{J}$ in gravitation measure ; the annexed values in ergs are calculated on the supposition that at Zurich the value of $g$ is $981 \cdot 5$.

Value derived from calculations based on the different specific heats of a gas, from experimental determinations by Gravitation
measure. Megalergs. Regnault and Röntgen

Value derived from experiments by $H$. F. Weber, on the heat developed by a known current whilst passing through a resistance measured in absolute measure by himself

Taking the mean of these values for $J(=428.55$ in gravitation measure), and determining the heat produced by a measured current in a circuit the resistance of which was measured by himself in absolute units, Weber obtained a mean value for the Siemens unit of resistance of $0.9550 \times 10^{9}$ C.G.S. units, employing a coil (No. 1914) obtained from W. Siemens as standard. By two other different methods (one depending on the determination of the rate of oscillation of a magnetic needle in a coil, the other on the measurement of the current induced in a given coil by opening a known current in an adjacent circuit) the resistance of this same standard coil was found to be respectively $0.9545 \times 10^{9}$ and $0.9554 \times 10^{9}$, giving as final average of the three series of observations, $0.9550 \times 10^{9}$ C.G.S. units. Unfortunately Weber did not compare his standard Siemens unit with any copy of the B.A. unit: assuming, however, that the Siemens unit used by him bore 
to the B.A. unit the same ratio as that found by Kohlrausch (§36), viz. 1 to $1 \cdot 0493$, the value of the B.A. unit becomes finally

$$
0.9550 \times 1.0493=1.0021 \text { earth-quadrant per second, }
$$

exhibiting an error in excess of $0.0021=0.21$ per cent.

Taking these results into consideration along with those of Kohlrausch and Lorenz, discussed in Part II., the following values are finally deducible for the Siemens and B.A. resistance units respectively in earth-quadrants per second:-

Siemens unit. B.A. unit.

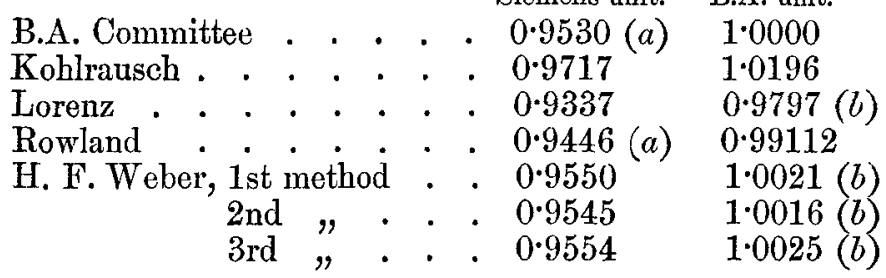

the values marked $(a)$ for the Siemens unit being derived from the observed value of the B.A. unit by dividing by 1.0493 , the ratio found by Kohlrausch, and those marked (b) for the B.A. unit being obtained by multiplying the observed values of the Siemens unit by 1.0493. Mr. Fletcher's preliminary results as above stated give a value less than 1.0000. Taking all these valuations into consideration, it would seem that, in the existing state of our knowledge, it is just about as probable that the B.A. unit is in error in deficiency as that it is erroneous in excess. Accordingly, in the following experiments it is assumed that the B.A. unit represents exactly one earth-quadrant per second, and in consequence that the E.M.F. of a Clark's cell is exactly, as determined by him, $1.457 \times 10^{8}$ C.G.S. units, or $1 \cdot 457$ theoretical volt.

56. Admitting this to be so, however, it does not seem to be possible that Joule's water-friction values of $\mathbf{J}$ are exact $(\S 34)$ : not only do the determinations of Hirn and Violle concur in indicating values for $J$ of from nearly 2 to 3 per cent. higher. than these water-friction values ( $\$ 37$ ), but, further, four different sets of observations also indicate that if the B.A. resistance-unit be correct ( $i . e$. if it $=1$ earth-quadrant per second), or if the Siemens unit be 0.9530 earthquadrant per second, the value of $J$ must be from 1 to 2 per cent. higher than these values, and, on the whole, upwards of 42 megalergs. These observations are, first, those of von Quintus Icilius (Pogg. Ann. ci. p. 65) as corrected by H. F. Weber (loc. cit. suprà), which were based on an erroneous 
early determination of the absolute value of a Jacobi resistanceunit by $W$. Weber ; after correction they indicate a value for $J$ of 431.6 in gravitation measure, or, assuming $g=981$, of 42.34 megalergs ; and, next, those of Joule himself, those of $\mathrm{H}$. F. Weber above quoted, and those of the author and Mr. Rennie (Part II.), which yield the following results :-

Value of $J$, the B.A. unit being supposed to be exactly 1 earth-quadrant per second.

Von Quintus Icilius (corrected by H. F. Weber) of which investigation have been $\}$ above $42 \cdot 10$ " shown to be too low $(\S 54)$.

H. F. Weber*, $42.02 \times \frac{1.0000}{1.0021}$. . 41.93 , $\left.\begin{array}{c}\text { Alder Wright and Rennie (value } \\ \text { slightly too low) . . . }\end{array}\right\}$ above 41.96 "

Moreover, as stated above, H. F. Weber has calculated, from Regnault's and Röntgen's experiments on the specific heats of air \&c., that $\mathrm{J}=42 \cdot 10$ megalergs. Hence, finally, taking into account all the above experiments, the most probable value of $J$ lies close to 42 megalergs, being above rather than below that value. Until further anthoritative determinations finally settle the question as to the true values of the B.A. unit and of $J$, the former may, as above stated, be considered to be exactly 1 earth-quadrant per second, and the latter may be safely taken as being 42 megalergs, most probably lying between $41 \cdot 75$ and $42 \cdot 25$ megalergs. In the following parts of of this paper, consequently, $\mathrm{J}$ is taken $=42 \times 10^{6} \mathrm{C}$.G.S. units, a $\chi$, the factor for reducing gramme-degrees to E.M.F. units (volts), is taken as being $=0.000105 \times 42 \times 10^{6}=4410.0$.

General Conclusions from the results of previous experimenters, and those subsequently detailed: Statement of Theorem relative to Polarization and the Nature of Electrolysis and the Amount of Work done therein.

57. It has been shown in Part I. ( $\$ 13-17)$ that the work expended in decomposing an electrolyte into the "nascent" products of electrolysis is not necessarily the same as that performed in breaking it up into the final products of electrolysis, and that by determining (in terms of E.M.F. or other-

* Weber's result refers to air-thermometer temperatures, those of the other experimenters to temperatures measured by the mercurial thermometer and not reduced to air-thermometer readings. 
wise) the two quantities, conclusions may be drawn as to the general nature of the phenomena connected with the "nascent state." If the difference of potential between the electrodes of an electrolytic cell be $\mathrm{E}$, during the passage of a quantity of electricity $Q$ sufficient to decompose a granıme of electrolyte in a time $t$ (thereby giving rise to a current $\mathrm{C}=\frac{\mathrm{Q}}{t}$ ) a total amount of work $\mathrm{EQ}=\mathrm{EC} t$ is done, of which $\mathrm{C}^{2} \mathrm{R} t=\mathrm{CQR}$ represents the work done as heat due to the resistance of the cell R (Joule's law, Part I. $\$ \S 1$ \& 2); consequently an amount $\mathrm{EQ}-\mathrm{C}^{2} \mathrm{R} t=(\mathrm{E}-\mathrm{CR}) \mathrm{Q}$ of work is done in decomposing the electrolyte into the nascent products of decomposition. The E.M.F. E-- CR representing this amount of work is readily measurable by electrical means; for it is the quantity sometimes spoken of as the "counter E.M.F. set up during electrolysis," being the value of $e$ in Ohm's theorem

$$
\mathrm{C}=\frac{\Sigma(\mathrm{E})-e}{\bar{\Sigma}(\overline{\mathrm{R}})+\mathrm{R}}
$$

where $\Sigma(\mathbf{E})$ is the sum of the electromotive forces of the battery, $e$ the counter E.M.F. set up, $\Sigma(\mathrm{R})$ the total resistance in circuit less that of the electrolytic cell, and $\mathrm{C}$ the current produced. For if $r$ be the "resistance of a wire obstructing the current equally with the electrolytic cell" (i.e. what may be conveniently termed the apparent resistance of the voltameter, equal to that of a wire through which the current $C$ would pass when a difference of potential $E$ subsisted between its ends), we have

whence*

$$
\mathrm{C}=\frac{\mathrm{E}}{r}=\frac{\Sigma(\mathrm{E})-e}{\Sigma(\mathrm{R})+\mathrm{R}}=\frac{\Sigma(\mathrm{E})}{\Sigma(\mathrm{R})+r} ;
$$

and

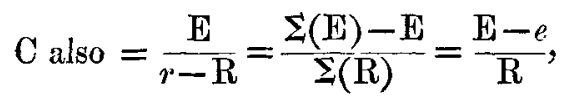

$$
e=\mathrm{E}-\mathrm{CR} \text {. }
$$

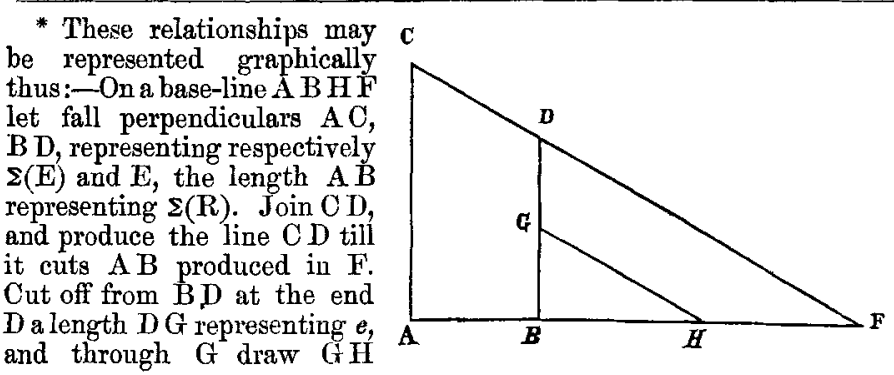

Phil. Mag. S. 5. Vol. 11. No. 67. March 1881. 
58. Very many experiments have been made during the last thirty or forty years on the values of $e$ under varying conditions, on a somewhat closely allied thing, viz. the E.M.F. existent between the electrodes of an electrolytic cell after rupture of the current*, and on the E.M.F. of gas-batteries (and especially those with hydrogen and oxygen as gases) $\dagger$. From these researches it results that, other things being equal, the counter E.M.F. set up during electrolysis increases with the current-strength as the size of the electrodes is diminished and as the temperature is lowered, at least within certain limits. The observations made have almost invariably been performed with currents of moderate or considerable magnitude; with such currents in no case has a value for $e$ been obtained less than the E.M.F. corresponding to the decomposition into the final products, whilst with powerful currents much larger:values have been obtained: thus with water, all values of $e$ registered lie above 1.50 volt, and sometimes exceed 3 volts (when reduced to that unit). Certain experiments of Andrews (Phil. Mag. [3] x. p. 433), and Buff (Ann. Chem. Pharm. xciv. p. 1), made by decomposing water with a feeble battery-power (less than 1:50 volt), appear, however, to show that a less value for $e$ may exist when a very minute current only is employed, in which case simultaneous evolution of hydrogen and oxygen does not take place; if the one or the other be prevented from

parallel to $\mathrm{CDF}$, cutting $\mathrm{AF}$ in $\mathrm{H}$. Then $\mathrm{BF}$ represents $r$, and $\mathrm{BH}$ represents R. And by similnr triangles,

or

$$
\frac{\mathrm{AC}}{\overline{\mathrm{A} F}}=\frac{\mathrm{AC}-\mathrm{BD}}{\overline{A B}}=\frac{\mathrm{AC}-\mathrm{DG}}{\mathrm{AH}}=\frac{\mathrm{BD}}{\overline{\mathrm{B}} \mathrm{F}}=\frac{\mathrm{BG}}{\overline{\mathrm{BH}}}=\frac{\mathrm{DG}}{\overline{\mathrm{H}} \overline{\mathrm{F}}},
$$

$$
\frac{\Sigma(\mathrm{E})}{\Sigma(\overline{\mathrm{R}})+r}=\frac{\mathbf{\Sigma}(\mathrm{E})-\mathrm{E}}{\Sigma(\overline{\mathrm{R}})}=\frac{\Sigma(\mathrm{E})-e}{\Sigma(\overline{\mathrm{R}})+\mathrm{R}}=\frac{\mathbf{E}}{r}=\frac{\mathbf{E}-e}{\overline{\mathbf{R}}}=\frac{e}{r-\overline{\mathbf{R}}} .
$$

* The term "polarization" is sometimes applied to mean the counter" E.M.F. of an electrolytic cell $e$ as above defined, sometimes the E.M.F. set up between the electrodes after the current has ceased to flow (a quantity always less than the value of $e$ existent whilst the current passes), and sometimes (perhaps most frequentily of all in a vague undefined sense), to express the fact that something or other takes place tending to diminish the current: thus the silver plate of a Smee's cell is said to become "polarized." In the subsequent parts of this paper the terms "counter E.M.F. of an electrolytic cell" and "subsequent polarization" respectively are used to indicate the first two of these meanings.

$\dagger$ At the request of the Publication Committee of the Physical Society a discussion of the results obtained by many previous observers bearing in these directions is omitted, together with the numerous references to their work. The best résumé of this work that the writer is acquainted with is in Wiedemann's Lehre vom Galvanismus, which, however, does not include a considerable number of researches published within the last few years. 
making its appearance as a free gas by using a large electrode and a minute one (Wollaston's point), a feeble evolution of gas may be noticed (especially at first) from the small electrode, but none from the other. Similarly, the experiments of Helmholtz on what he terms "electrolytic convection" (Phil. Mag. [4] xlvii. p. 152), and analogous observations of others, show that, if the one or the other gas is suppressed by the chemical action of other kinds of gas respectively dissolved in the fluid surrounding the electrode or adherent to the electrode surface, water may be decomposed by an E.M.F. of less than 1.50 volt.

59. As regards "subsequent polarization," or the E.M.F. existent between the electrodes of an electrolytic cell after the original current has been ruptured, even when measured by a quick-working switch or "wippe," it results from the observations at present on record that a more or less perceptibly smaller value is always obtained than corresponds to the counter E.M.F. set up whilst the current was passing. Under certain circumstances, especially when currents of short duration are employed, the difference becomes very marked; so that on the whole "subsequent polarizations" have been recorded, for acidulated water for instance, of magnitude varying from something upwards of two or even three volts to something less than $\cdot 001$ volt. With currents producing smaller values than 1.5 volt (measured immediately after rupture) visible evolution of gas at both poles does not seem to have ever been noticed. Recently Exner (Wied. Annalen, vi. p. 336,1870 ) has shown that to cause visible evolution of gas from boiled-out distilled water, a "subsequent polarization" (measured immediately after rupture by a quadrant electrometer) of from 2.03 to 2.09 Daniell cells (from $2 \cdot 2$ to $2 \cdot 3$ volts) must be established; whilst if the water be faintly acidulated, a polarization of about $1 \cdot 89$ Daniell $=2 \cdot 1$ volts is sufficient. And in the same paper he has also shown that the polarization set up after the current is ruptured differs from the E.M.F. of the battery employed (and a fortion from the counter E.M.F. set up during the passage of the current) only by quantities too small to measure accurately by a quadrant electrometer, when the battery E.M.F. does not exceed from 1.40 to 1.47 Daniell cell $(1.54$ to $1 \cdot 61$ volt) when larger platinum plates and boiled-out dilute acid are used, and from 1.94 to $2 \cdot 09$ Daniell cells ( $2 \cdot 1$ to $2 \cdot 3$ volts) with Wollaston's points (platinum wires coated with glass, so as only to expose a minute surface at the ends) ; whilst with stronger battery electromotive forces than these values the subsequent polarization always falls sensibly short of the battery E.M.F.

$$
\mathrm{O} 2
$$


60. Various determinations have been made of the E.M.F. which a Grove's gas-battery can generate under various conditions. When the gases are oxygen and hydrogen, it has uniformly been found that the E.M.F. generated is less than 1.50 volt, the value representing the work done in the union of ordinary gaseous oxygen and hydrogen to form liquid water, which is the end result of the action taking place in such a cell when it generates a current. Recently Osgood Pierce (Wied. Annalen, viii. p. 98, 1879) has found numbers varying from $\cdot 766$ to .926 Daniell cell ( .84 to 1.02 volt), according to the temperature, the nature of the liquid present, the purity of the oxygen, \&c. Cateris paribus, increasing the temperatures lowers the E.M.F ; Morley has recently shown (Proceedings Physical Society, ii. p. 212, 1878) that when a Grove gas-battery produces a current the E.M.F. is not constant, but is a function of the current produced, being the smaller the greater the current, i.e. the less the external resistance, and vice versa.

61. A clear coherent explanation of the differences in the numerical values of these quantities obtainable under various conditions, accounting quantitatively for them, and consistent with well-known dynamical principles, does not appear as yet to have been brought prominently forward; the following attempt in that direction is the result of a somewhat prolonged experimental investigation, some of the results of which are detailed subsequently.

Theorem.-Were it possible that the surface-action of the electrodes, the chemical action of substances dissolved in the fluid electrolysed, or of the electrode materials themselves, and other interfering causes (such as the accumulation of fluids of different densities round the electrodes) could be entirely eliminated, the primary effect of electrolysis would be to break up the electrolyte into "nascent" products, the formation of which would correspond to a definite amount of work, and con= sequently to a definite E.M.F.; but the physical attraction exerted by the electrodes upon the nascent products causes a certain proportion of them (variable with circumstances) to be converted al initio into products, the formation of which from the "nascent" products is accompanied by a gain of energy (or evolution of heat). Similarly, under certain conditions the products of electrolysis are chemically acted upon by the electrodes, or by gases occluded upon their surfaces, substances dissolved in the fluid electrolysed, \&c. ; whilst, as the action proceeds, solutions of different densities accumulate round the electrodes, tending to set up an E.M.F. in virtue of their interdiffusion. All these circumstances modify the 
amount of work actually performed by the curent whilst causing electrolysis, in such a way that the algebraic sum of the energy gained by these other actions is subtracted from the energy that would otherwise be required to break up the electrolyte into nascent products.

This theorem may be put in the form of the following equation.-Suppose that the quantity of total products of electrolysis at the negative electrode be called 1, and out of this amount let $1-n_{1}$ parts be evolved "nascent," whilst $n_{1}$ parts are so affected by the condensing or attractive action of the electrode as to be evolved ab initio not in the "nascent" condition, but in a more condensed form, viz. in the ordinary physical condition of the substance, if non-gaseous, but, if naturally gaseous, in the form of a more or less condensed form of gaseous matter (occluded gas, quasi-liquefied gas, or gas strongly attracted to the surface of the electrode). Let $\mathrm{H}_{1}$ be the heat evolved per gramme-equivalent of product in its transformation from the "nascent" to the ordinary free condition, and let $h_{1}$ be the heat evolved in further condensing a gramme-equivalent of the substance to the more condensed form in which the fraction $n_{1}$ of total product is evolved. Similarly let $n_{2}, \mathrm{H}_{2}$, and $h_{2}$ be the values corresponding respectively to $n_{1}, \mathrm{H}_{1}$, and $h_{1}$, referring to the products at the + electrode taken as unity. Then the amount of energy to be subtracted from that corresponding to the decomposition into the nascent products due to the attractive action of the electrodes is given in terms of E.M.F. by the expression

$$
\left\{n_{1}\left(\mathrm{H}_{1}+h_{1}\right)+n_{2}\left(\mathrm{H}_{2}+h_{2}\right)\right\} \chi \mathrm{J} .
$$

The energy corresponding to the work done in the decomposition into nascent products being expressed in terms of E.M.F. by $\mathrm{E}_{\iota}$, let $\Sigma(\mathbf{H})$ represent the heat-evolution per gramme-equivalent of substance decomposed, due to the algebraic sum of the chemical actions taking place between the products and the electrodes, \&c., and of the diffusive action of the differently constituted liquids surrounding the two electrodes; then the final E.M.F. corresponding to the work done in electrolysis will be

$$
e=\mathrm{E}_{l}-\left\{n_{1}\left(\mathrm{H}_{1}+h_{1}\right)+n_{2}\left(\mathrm{H}_{2}+h_{2}\right)+\Sigma(\mathbf{H})\right\} \chi \mathrm{J} .
$$

If now $\mathrm{E}_{1}$ represent the E.M.F. corresponding to the work done in decomposing the electrolyte into the final products, supposing them to escape in the ordinary free condition,

$$
\mathrm{E}_{1}=\mathrm{E}_{l}-\left(\mathrm{H}_{1}+\mathrm{H}_{2}\right) \chi^{\mathrm{J}} \text { : }
$$


whence

$$
e=\mathrm{E}_{1}+\left\{\left(1-n_{1}\right) \mathrm{H}_{1}-n_{1} h_{1}+\left(1-n_{2}\right) \mathrm{H}_{2}-n_{2} h_{2}-\Sigma(\mathbf{H})\right\} \chi \mathrm{J},
$$

which may for shortness be written

$$
e=\mathrm{E}_{\mathbf{1}}+[\Sigma\{(1-n) \mathrm{H}\}-\Sigma(n h)-\Sigma(\mathbf{H})] \chi \mathrm{J} .
$$

62. According to the particular values which the several terms in this expression may have, various values for $e$ may be deduced. On examination it is found that all the apparently abnormal variations in the value of the counter E.M.F. set up during electrolysis, of the subsequent polarization, and of the closely allied E.M.F. produced by gas-batteries and analogous combinations may be satisfactorily accounted for by this expression *. Thus, for instance, suppose water to be electrolysed with platinum poles, so that no chemical action takes place between the electrodes and the products, whilst no suppression of hydrogen by the action of dissolved oxygen, or of hydrogen by dissolved oxygen takes place; then $\Sigma(\mathbf{H})=0$. If now the electrode be supposed to be destitute of adherent or occluded gases to commence with, and the current be very minute, the whole of the water decomposed will be transformed into hydrogen and oxygen in a highly condensed form, whence, since $n_{1}=1$ and $n_{2}=1$,

$$
e=\mathrm{E}_{1}-\left(h_{1}+h_{2}\right) \chi \mathrm{J}=\mathrm{E}_{1}-\Sigma(h) \chi \mathrm{J} .
$$

Under such conditions therefore the water will be electrolysed by an E.M.F. less than 1.50 volt (the value of $\mathrm{E}_{1}$ ), Experiment shows in fact that when well-boiled water (either nearly pure or acidulated with sulphuric acid) is decomposed with recently ignited platinum electrodes, an E.M.F. scarcely appreciably greater than 0 will suffice to enable a current to pass, whence $\left(h_{1}+h_{2}\right) \chi \mathrm{J}$ must, under these conditions, nearly $=1.50$ volt,

or $h_{1}+h_{2}$ must nearly $=34,100$ gramme-degrees;

that is, the heats of condensation of oxygen and hydrogen by platinum \& c. jointly may amount to almost as large a quantity as that developed by their union to form liquid water.

That the work done in the condensation of a film of gas by attraction to or occlusion in a solid body is great relatively to the mass of gas condensed is well known. The Author, con-

* At the request of the Publication Committee of the Physical Society, the discussion of several particular cases of this theorem and of their bearing upon and explanation of various phenomena observed by previous experimenters is omitted. 
jointly with Prof. W. C. Roberts, has shown (Chem. Soc. Journal, 1873, p. 112) that the specific heat of the portion of hydrogen first occluded by palladium is much greater than that of the later portions, the limiting values being near to 9 on the one side and $3 \cdot 4$ on the other-or values respectively representing a condensation to something approaching the liquid state (judged by analogy with liquid bromine, the product of the combining number and specific heat of which is near 9), and a condensation but little exceeding that due to ordinary atmospheric pressure. Presumably when a film of gas is attracted to the surface of a solid, the portions first attracted are very highly condensed, the next ones less so, and so on, a kind of atmosphere or aura surrounding the body being thus produced of density varying from the maximum amount of condensation to the minimum, $i$. e. the pressure of the surrounding atmosphere. The total quantity of gas thus condensed is not inconsiderable: thus an ordinary porcelain or, better still, a platinum crucible, if ignited and cooled in dry air, will weigh less by from one to several milligrammes, according to its size, if weighed immediately it is cold, and before the film or aura of condensed gas expelled by the heat is completely re-formed, than it will weigh if allowed to remain some time in the dry air, and weighed after the aura has been attracted to saturation. The inequality in the deviations from Boyle's law exhibited by gases under high pressures, but when still far removed from their condensing or from their critical points, has been considered by many physicists to be probably largely due to the difference in the attracting or aura-forming capacity exhibited by the tubes and measuring-vessels used, according as the nature of the gas varies. Not only gases, but also liquids, are attracted by solids, forming a layer or aura of highly condensed liquid adherent to the solid : Schliermacher has recently calculated (Dingler, Pol. Journal, pp. 224, 471; Chemical-Society Journal, Abstracts, 1880, p. 363) that this causes an appreciable error in the determinations of the weight of a unit volume of water hitherto made.

63. When water is electrolysed with non-oxidizable recently ignited electrodes (e.g. of platinum), the length of time which must elapse before the electrodes become saturated with gases will depend on circumstances, and amongst others on the fact that the water will tend to take up oxygen at the + electrode and hydrogen at the - electrode, and the solutions thus produced will diffuse towards the opposite poles, thus tending to set up a double form of "electrolytic convection."

Suppose that a current pass through acidulated water, so that gases are slowly evolved; if by saturating with oxygen 
the water surrounding the - electrode the hydrogen is wholly reconverted into water, leaving out of sight the formation of liquids of differing densities round the two electrodes, and supposing that the + electrode and fluid surrounding it are saturated with oxygen, it will result that

$$
\Sigma(\mathbf{H})=\mathrm{E}_{1}+\left\{\left(1-n_{1}\right) \mathrm{H}_{1}-n_{1} h_{1}\right\} \chi \mathrm{J}
$$

(the $n_{1}, \mathrm{H}_{1}$, and $h_{1}$, referring to hydrogen), whence

$$
e=\left\{\left(1-n_{2}\right) \mathrm{H}_{2}-n_{2} h_{2}\right\} \chi \mathrm{J} \text {. }
$$

Now when $n_{2}=0$ this value is + , being $\mathrm{H}_{2} \chi \mathrm{J}$; but if $n_{2}=1$ it would become negative, $=-h_{2} \chi \mathrm{J}:$ for certain values of $n_{2}$ therefore (i.e. for certain rates of current-flow, Part IV.), the value of $e$ whilst still + must be less than 1.50 volt; $i$. e. when "electrolytic convection" takes place, so that the hydrogen evolved by electrolysis is reoxidized as fast as generated, electrolysis may be produced by means of a less E.M.F. than 1.50 volt. Obviously the same result follows if the hydrogen be unoxidized, but the oxygen be reconverted into water by dissolved hydrogen ; and the same may ensue if only a part of the hydrogen or oxygen is thus reconverted into water.

64. Again, when $\Sigma(\mathbf{H})$ is negligible compared with the other terms, and $n_{1}$ and $n_{2}$ are both small, the value of $e$ may be greatly superior to $\mathrm{E}_{1}$; for when $n_{1}$ and $n_{2}$ are both $=0$ and $\Sigma(H)$ is negligible,

$$
e=\mathrm{E}_{1}+\left(\mathrm{H}_{1}+\mathrm{H}_{2}\right) \chi \mathrm{J}=\mathrm{E}_{l} .
$$

Experimentshows that, cateris paribus, the stronger the current the smaller are the values of $n_{1}$ and $n_{2}$; that is, $e$ continually increases as the current increases, tending towards a limiting value in any given case (Crova, Ann. Chim. et Phys. Ixviii. p. 413,1868$)$. Although at present the data for calculating accurately the limiting values of $\mathrm{E}_{l}$ for various substances are not extant, yet it is known that in the case of water $\mathbf{E}_{l}$ must be upwards of 3 volts; for values of $e$ above 3 volts have been observed : that is, the value of $\mathrm{H}_{1}+\mathrm{H}_{2}$ is greater than 34,100 gramme-degrees; or the heat of transformation of the "nascent" products of electrolysis of water into gaseous oxygen and hydrogen jointly exceeds the heat developed by the combination of these gases at ordinary temperature and pressure to form liquid water.

The theorem therefore accounts for all possible variations in the counter E.M.F. set up during electrolysis, between the minimum values (when the normally gaseous products of electrolysis are evolved not as free gases, but as condensed 
films of attracted or occluded gas, or when they are chemically acted upon by the electrodes or other substances in contact with them, e. g. during the so-called "electrolytic convection" of Hemholtz) and the limiting maximum reached with an indefinitely large current.

65. Before passing from this point it is worth noticing that the circumstance that the limiting value of $\mathrm{E}_{l}$ for water must lie above 3 volts shows that the first action of the current can be neither of the three following changes :-

$$
\begin{aligned}
& \text { (1) } 2 \mathrm{H}_{2} \mathrm{O}=\mathrm{H}_{2} \mathrm{O}_{2}+\mathrm{H}_{2} \text {; } \\
& \text { (2) } 3 \mathrm{H}_{2} \mathrm{O}=3 \mathrm{H}_{2}+\mathrm{O}_{3} \text {; } \\
& \text { (3) }\left\{\begin{array}{l}
\mathrm{H}_{2} \mathrm{O}+\mathrm{H}_{2} \mathrm{SO}_{4}=\mathrm{H}_{2}+\mathrm{H}_{2} \mathrm{SO}_{5} \\
\text { or } \mathrm{H}_{2} \mathrm{O}+2 \mathrm{H}_{2} \mathrm{SO}_{4}=\mathrm{H}_{2}+\mathrm{H}_{4} \mathrm{~S}_{2} \mathrm{O}_{9}
\end{array}\right.
\end{aligned}
$$

forming respectively gaseous hydrogen and hydrogen dioxide, gaseous hydrogen and ozone, and gaseous hydrogen and the "persulphuric acid" of Berthelot; for that observer has shown (Bulletin Soc. Chim. Paris, 1876, xxvi. p. 56, and 1880, xxxiii. p. 246), that the amounts of heat absorbed by the addition of 8 grammes of oxygen to 9 of water to form hydrogen dioxide, to 16 of oxygen forming ozone, and to sulphuric acid forming persulphuric acid, are respectively $10,800,14,800$, and 13,800 gramme-degrees; so that the transformation of 8 grammes of ordinary oxygen into 8 of ozone would absorb $\frac{14,800}{3}=4933$ gramme-degrees, and the above three decompositions would absorb per grammeequivalent (1 gramme of hydrogen evolved) respectively $34,100+10,800=44,900,34,100+4933=39,033$, and 34,100 $+13,800=47,900$ gramme-degrees, corresponding to the setting-up of counter electromotive forces amounting respectively to only $1.98,1.72$, and 2.11 volts, or far below the actual maximum. Even, therefore, if it be admitted that persulphuric acid is the body of which the oxygen that finally escapes is first produced as a constituent, it must be supposed that the hydrogen is evolved as an allotropic modification absorbing heat in its formation from ordinary gaseous hydrogen ; whilst if this be admitted for hydrogen, it seems at least probable that the same is true for oxygen, and that the hydrogen dioxide, persulphuric acid, and ozone, found to be formed under certain conditions, are secondary products due to the reaction of the "nascent" oxygen on water or sulphuric acid, or to its "rearrangement" into ozone, just as the oxygen ultimately developed is due to a further rearrangement. 
In accordance with the ordinarily received views as to the atomic and molecular constitution of matter, it would seem to result from the fact that the maximum counter E.M.F. set up during electrolysis of water exceeds 3 volts, that the first action of the current is to break up the water (and similarly for other electrolytes) into free atoms of the components, which atoms then rearrange themselves into molecules either as a secondary action or under the condensing action of the electrodes, or both; whence it would seem that the sum of the heat of condensation of hydrogen atoms to molecules together with that of oxygen atoms to molecules exceeds that of the union of the hydrogen and oxygen atoms together to form molecules of liquid water.

66. The phenomena connected with " subsequent polarization " ( $\$ 58$, footnote) are just as readily explained by the theorem as those relating to the counter E.M.F. set up whilst the current is passing. When visible decomposition has taken place for some time, so that the electrodes are surrounded respectively with a saturating aura of bydrogen and of oxygen, varying in density from the highest to the lowest possible value, and when, in addition, there are in the vicinity of the electrodes more or less of the "nascent" products of electrolysis, the counter E.M.F. set up during the passage of the current, and therefore representing the polarization at the instant of rupture, is $(\$ 61)$

$$
e=\mathbf{E}_{1}+[\Sigma\{(1-n) \mathrm{H}\}-\Sigma(n h)-\Sigma(\mathbf{H})] \chi \mathrm{J} .
$$

After the lapse of a given interval of time (however small), more or less of the "nascent" products have spontaneously changed into the final products, viz. oxygen and hydrogen, thereby diminishing the value of $\Sigma\{(1-n) H\}$, and consequently lessening the value of $e$, the "polarization." Even after sufficient time has elapsed for the whole of the "nascent products" to have thus transformed themselves, the diffusion of water containing dissolved oxygen to the hydrogen electrode from the other, and of water containing dissolved hydrogen from the hydrogen electrode to the other, will still cause, by chemical action, a continual removal of portions of the aurn of attracted gas round each electrode, thereby causing a continual increase in the mean value of $\Sigma(n h)^{*}$, and hence a further diminution in the value of $e$; finally the polarization must become 0 , when

$$
\{\Sigma(n h)+\Sigma(\mathbf{H})\} \chi \chi^{J}=\mathrm{E}_{1}=1.50 \text { volt } .
$$

* Gladstone and Tribe have shown (Chem.-Soc. Journ. Trans. 1878, p. 306) that hydrogen condensed by surface-attraction upon or occluded by certain solids (e.g. palladium, platinum, or carbon) exerts a mueh 
Experiments on the rate of diminution of the "subsequent polarization " and the circumstances influencing it are detailed later on $(\$ 69$ et seqq.).

67 . When an electrolytic cell (e. g. a voltameter), the electrodes of which are destitute of attracted films of gas or occluded gases, is connected with an electromotor and a current of very short duration sent through it, if the amount of decomposition produced be so small that the hydrogen- and oxygen-development equivalent to the quantity of electricity passing are only small fractions respectively of the amount requisite to saturate the electrodes, no visible development of gas will ensue; the polarization at the instant of rupture of current will then be $(\$ 62)$

$$
e=\mathrm{E}_{1}-\Sigma(h) \chi \mathrm{J},
$$

the value of $h$ depending on the particular amounts of condensation to which the evolved products are condensed. On passing the current from the same electromotor for the same time again, a slightly less amount of current will flow; for the mean counter E.M.F. set up during this second interval of time will be somewhat greater than that during the first, whilst the total resistance in circuit is the same, whence the current (which $\left.=\frac{\Sigma(\mathrm{E})-e}{\Sigma(\mathrm{R})+\mathrm{R}}, \S 57\right)$ must lessen. Similarly, on passing the current again and again for equal intervals of time, quantities of electricity will pass in each interval, gradually diminishing in amount; whilst the "subsequent polarization" continually increases, the roltameter acting as a condenser, the capacity of which is simply measured by the power of the electrodes to condense upon their surfaces and occlude internally the products of electrolysis. On discharging a charged condenser by causing it to generate a regular succession of currents of equal but very short duration as to

more energetic reducing action upon various substances than ordinary free hydrogen, the same result for palladium charged with occluded hydrogen (so-called hydrogenium) having been previously observed by Graham (Proc. Roy. Soc. xvii. p. 212, 1869). This result is not due to the condensed hydrogen being capable of evolving more heat by action on the substances in question than would be produced by the same quantity of free gaseous hydrogen, because the reverse is the case, the difference being the heat given out in condensing the hydrogen from the ordinary gaseous condition to the condensed form obtaining in the particular cases in question. The "catalytic" action of spongy platinum exemplified in Dobereiner's lamp; for instance, also illustrates this fact. The effect of the condensation, therefore, is analogous to that of increased temperature, causing chemical actions to take place that would not ensue (at least at any measurable rate) under other conditions, $i . e$. less condensation or lower temperature respectively. 
time, the quantity of electricity conveyed in each interval must at first be nearly the same, but will gradually diminish. These and various other analogous points in connexion with the behaviour of a voltameter as a condenser have recently been quantitatively studied by Herwig (Wied. Ann. ii. p. 601, and vi. p. 305), whose results are perfectly in accordance with the deductions from the general theorem above stated.

68. It is evident that the considerations that apply to the form of voltaic combination produced by the products of decomposition formed by the passage of a current through the decomposing-cell will equally apply if the same products of decomposition are introduced into the cell in other ways; so that if two platinum plates are exposed, the one to water impregnated with ordinary oxygen gas, the other to water containing dissolved hydrogen, the two waters meeting, the attractive action of the plates will cause a more or less nearly saturated aura to be formed round each plate, and a difference of potential will be set up between the plates representing the work that would be gained by the combination of the condensed oxygen and hydrogen : in fact, the form of Grove's gas-battery thus produced will be identical in all respects with that developed when water is decomposed in a voltameter, except that in the latter case the polarization is more or less enhanced by the presence of the "nascent" products of electrolysis, at least until these have become wholly converted into the ultimate products. Such a gas-battery must therefore develop an E.M.F. expressed by the value of the formula

$$
e=\mathrm{E}_{1}+[\Sigma\{(1-n) \mathrm{H}\}-\Sigma(n h)-\Sigma(\mathbf{H})] \chi^{\mathrm{J}}
$$

now obtaining; that is, since $n=1$,

$$
e=\mathrm{E}_{1}-\{\Sigma(h)+\Sigma(\boldsymbol{H})\} \chi \mathrm{J},
$$

or, since $\Sigma(\mathbf{H})$ must be extremely small, if not wholly negligible, practically,

$$
e=\mathrm{E}_{1}-\Sigma(h) \chi \mathrm{J} \text {. }
$$

Hence the E.M.F. of a hydrogen and oxygen gas-battery cannot exceed 1.50 volt, which experimentally is found to be the case. Any thing that affects the value of $\Sigma(h) \chi \mathbf{J}$ must affect the E.M.F. of a gas-battery; accordingly the E.M.F. is found to vary largely with the temperature, the nature of the plates, the fluid in which the gases are dissolved, the state of concentration of the gas-solutions therein, the presence of other gases, \&c.; and in particular it is found to diminish with the strength of the current generated (Morley, loc. cit. suprò); for the more rapidly the films or auræ of gases attracted and those occluded are used up by chemical 
action, the less will be the mean densities of the aurx, and hence the greater will be $\Sigma(h)$ and the less the value of $e$.

Experiments on the Influence of dissolved Gases on the Rate of Fall of the Polarization existent after vipture of the original current (Subsequent Polarization).

69 . It results from the general theorem above stated $(\S 61)$, that the rate of fall of the "subsequent polarization" in any given electrolytic cell (e.g. a voltameter) must be more rapid when the circumstances are such as to increase the numerical value of the term $\Sigma(\mathbf{H})$ than when the term is negligible; that is, the rate of fall must be a minimum (under any given conditions) when the fluids surrounding the electrodes (themselves unattacked by the products of electrolysis) have no chemical or physical action on these products, and when the electrodes have attracted and occluded as much of the products as they possibly can, but must be greater when these conditions are not fulfilled; so that in any ordinary voltameter, if the fluid surrounding the - electrode contain dissolved oxygen, the rate of fall must be greater than would be the case if no dissolved oxygen were present to act on the hydrogen aura; whilst, cceteris paribus, the larger the electrodes within certain limits, the less will probably be the effect of the oxygen dissolved in a limited amount of surrounding fluid on the hydrogen aura as a whole. Experiments on the rate of fall of "subsequent polarization" have been already made by Ayrton and Perry (Journ. Tel. Eng. v. p. 391, 1876), and the results expressed as curves; these observers, however, did not particularly examine the influence of varying amounts of dissolved air \&c. on the rate of fall. On the other hand, Helmholtz, Fleming, and others have noticed that when water freed from dissolved air by boiling is electrolysed, the "subsequent polarization" diminishes less rapidly than when water containing dissolved air is employed.

The mode of observation adopted for the purpose of verifying the above deductions from the theorem was much the same as that used by Ayrton and Perry (loc. cit.). The electrodes of a given voltameter were connected with an electrometer, a suitable resistance being also in circuit, so that a current of known strength could be passed for any required length of time : to measure the current passing it was found convenient to employ a method based on Ohm's law, viz. reading off the difference of potential set up by the current between the ends of a known resistance by means of a quadrant-electrometer. This method, first, is independent of the errors (due to possible change of zoro, horizontal magnetic component, \&c.) of ordinary galvanometers, which cannot conveniently be verified 
without throwing them out of eircuit or otherwise varying the current passing by altering the total resistance in circuit, which is impracticable in experiments in which it is essential that the current should not sensibly vary during long periods of time,-and, secondly, enables the value of an extremely minute current to be determined with as much accuracy as that of a much stronger one, and even with greater accuracy; for whilst the current from a given electrometer is diminished by throwing more and more resistance into circuit, the difference of potential between the ends of the resistance thus thrown into circuit is not only not decreased but is even increased. For if $e_{1}$ be the E.M.F. of the electrometer, $R_{1}$ the resistance the difference of potential between the ends of which $e_{2}$ is measured, and $R_{2}$ the resistance of the rest of the circuit, the current passing

whence

$$
\mathrm{C}=\frac{e_{2}}{\mathrm{R}_{1}}=\frac{e_{1}}{\mathrm{R}_{1}+\mathrm{R}_{2}}
$$

$$
e_{1}-e_{2}=\mathrm{CR}_{2} \text {. }
$$

Hence, as $\mathrm{C}$ diminishes $\dot{e}_{2}$ increases, and consequently a larger electrometer-deflection is obtained with a smaller current. Tolerably strong currents develop appreciable amounts of heat in the resistance-wire, thus increasing its resistance and introducing an error in deficiency in the current; so that the method is more particularly applicable for minute currents.

70. The difference of potential set up between the electrodes of a voltameter by the passage of a current $\mathrm{C}$ is $\mathrm{E}=e+\mathrm{CR}$, where $e$ is the counter E.M.F. set up, and $R$ the resistance of the voltaneter $(\$ 57)$. If $R$ do not exceed $100 \mathrm{ohms}\left(100 \times 10^{9}\right.$ C.G.S. units of resistance), and $\mathrm{C}$ do not exceed 0.0001 weber $\left(0^{\circ} 00001\right.$ C.G.S. current-unit), the value of $C$ Rdoes not exceed $100 \times 10^{9} \times 0.00001=0.01 \times 10^{8}=0.01$ volt; whilst, whatever the value of $C$ and $R$, the E.M.F. equal to the product $C R$ is readily calculable. If now the difference of potential between the electrodes $\mathrm{E}$ be read off (in terms of the scale of the quadrantelectrometer) whilst the current is passing, by noticing the deflection of the spot of light from the zero (readings being taken on one side only), and the current be then interrupted, a motion backwards of the spot through a scale-length equivalent to $C R$ will instantly ensue, and subsequently a continuous motion backwards as the value of $e$ falls; if, however, CR be equivalent to considerably less than half a scale-division of the electrometer, the first sudden motion backwards will be entirely inappreciable. In the following experiments the electrometer was so arranged that 1 scale-division represented about 0.02 volt (readings being taken on one side only of the 
zero); and consequently as long as CR was less than $0 \cdot 01$ volt (i. e. as long as $\mathrm{R}$ did not exceed 100 ohms and $\mathrm{C} 0.0001$ weber) the first sudden motion was less than 0.5 scale-division and was consequently practically inappreciable.

(I.) Surface of each platinum electrode $3 \cdot 2$ square centims. Value of $R=7 \cdot 6 \mathrm{ohms} ; \mathrm{C}=\cdot 000005$ to $\cdot 0001$ weber ; so that CR was quite negligible; value of $\mathrm{E}$ at moment of rupture of current $=1.60$ volt (average). The following numbers were obtained as the average of a number of concordant observations; the differences between the values obtained on repetition of an experiment were, as might be expected, much greater in the experiments of the A class than in the others.

Fall of $\mathrm{E}$ in volts.

\begin{tabular}{|c|c|c|c|}
\hline $\begin{array}{l}\text { Time in seconds } \\
\text { since rupture of } \\
\text { current. }\end{array}$ & $\begin{array}{c}\text { A. } \\
\text { Unboiled acid. }\end{array}$ & $\begin{array}{c}\text { B. } \\
\text { Acid well boiled } \\
\text { and used as soon } \\
\text { as cold. }\end{array}$ & $\begin{array}{c}\text { C. } \\
\text { Voltameter } \\
\text { charged with } \\
\text { acid saturated } \\
\text { with hydrogen } \\
\text { and oxygen at } \\
\text { the two elec- } \\
\text { trodes respec- } \\
\text { tively. }\end{array}$ \\
\hline $\begin{array}{r}5 \\
10 \\
15 \\
20 \\
30 \\
60 \\
120 \\
180\end{array}$ & $\begin{array}{l}.25 \\
.33 \\
.39 \\
.43 \\
.48 \\
.59 \\
.70 \\
.75\end{array}$ & $\begin{array}{l}\cdot 20 \\
.25 \\
\cdot 32 \\
.37 \\
\cdot 45 \\
.58 \\
.70 \\
.75\end{array}$ & $\begin{array}{l}\cdot 09 \\
\cdot 13 \\
\cdot 15 \\
\cdot 17 \\
.20 \\
.26 \\
.33 \\
.35\end{array}$ \\
\hline
\end{tabular}

(II.) Surface of each electrode 8,0 square centims. Value of $R=11 \cdot 2$ ohms, current $\cdot 000005$ to $\cdot 0001$ weber; so that $\mathrm{CR}$ was practically negligible. Arerage value of $\mathrm{E}$ at moment of rupture of current 1.80 volt.

Fall of E in volts.

\begin{tabular}{|c|c|c|c|}
\hline Time in seconds. & A. & B. & C. \\
\hline $\begin{array}{r}5 \\
10 \\
15 \\
20 \\
30 \\
60 \\
120 \\
180\end{array}$ & $\begin{array}{r}\cdot 26 \\
\cdot 33 \\
\cdot 39 \\
\cdot 43 \\
\cdot 48 \\
\cdot 52 \\
\cdot 56 \\
\cdot 58\end{array}$ & $\begin{array}{l}\cdot 22 \\
\cdot 27 \\
\cdot 30 \\
\cdot 32 \\
\cdot 36 \\
\cdot 38 \\
\cdot 40 \\
\cdot 41\end{array}$ & $\begin{array}{l}\cdot 19 \\
\cdot 23 \\
\cdot 25 \\
\cdot 26 \\
\cdot 28 \\
\cdot 29 \\
\cdot 295 \\
\cdot 30\end{array}$ \\
\hline
\end{tabular}

In precisely the same way analogous numbers were obtained in many other series of experiments, the details of which it is unnecessary to quote. Whether the electrodes were of gold, 
platinum, or carbon, whatever their size, and whatever the value of $\mathrm{E}$, in all cases the general character of the numbers was the same as in these two examples; i. e. the rate of fall with acid containing dissolved air was greater than that with acid freed from the greater part of the air dissolved by boiling; whilst this again was greater than that with acid from which the last traces of dissolved air had been removed (from the fluid surrounding the hydrogen-pole) by the slow evolution of hydrogen therefrom, so as to saturate the fluid with hydrogen and remove the dissolved oxygen by "electrolytic convection." As the removal of the last traces of oxygen became more and more nearly effected, the rate of fall of polarization (for a given initial value) graduclly approached a minimum value, beyond which it never sank, this minimum doubtless representing the rate of alteration produced in the auræ by diffusion from one electrode to the other.

71. The following experiments are specimens of a number of other analogous ones, all of which yielded the same general result, viz. that, other things being equal, the rate of fall of polarization is less the larger the electrode surface. The voltameters were precisely like those used in the above experiments, consisting of U-tubes with pieces of platinum-foil bent into cylinders and attached to platinum wires fused into glass tubes which served as mercury-cups-access of external air being prevented by closing each of the two open ends of the U-tubes with a doubly perforated cork (of india rubber, or paraffin), the mercury-cup tube passing air-tight through one perforation and a delivery-tube (bent over and dipping under mercury or oil) through the other, so that evolved gas could escape without admission of air. The voltameters, being filled with boiled acid containing about 27 grammes of $\mathrm{H}_{2} \mathrm{SO}_{4}$ per 100 cubic centims., were then connected with a pair of Minotti cells, a large resistance being in circuit; so that a feeble current passed, evolving one or two cubic centims. of bydrogen per day. After some days (generally a week to a fortnight) the minimum rate of fall of polarization was arrived at; when this was the case, the electrodes were kept for another day at some particular difference of potential, arrived at by suitably altering the current passing and experimented with throughout, and a series of observations made; the electrodes were then again brought to the same difference of potential by passing the current again for some time, and another series of observations made; and so on. Finally, the following values were obtained from several such series of concordant observations, the experiments being alike in every respect save size of electrodesthe strength of the acid and the distance apart of the nearest portions of the electrodes being as nearly as possible the same 
throughout, and the U-tube being the same; so that diffusion must have gone on at as nearly as possible the same rate throughout. The numbers in the column headed "largest" were obtained with electrodes each exposing 27.5 square centims. surface; those in the columns headed "medium" and "smallest" with electrodes exposing respectively 3.2 and 0.2 square centims. of surface. In every case the value of CR was practically inappreciable.

(I.) Value of $\mathrm{E}$ on breaking circuit $=1.60$ volt.

Fall of $\mathrm{E}$ in volts.

\begin{tabular}{|c|c|c|c|}
\hline Time,in seconds. & Largest. & Medium. & Smallest. \\
\hline 5 & .05 & .09 & $\cdot 19$ \\
10 & .08 & .13 & $\cdot 27$ \\
20 & $\cdot 10$ & .17 & $\cdot 37$ \\
30 & $\cdot 12$ & .20 & $\cdot 46$ \\
60 & .15 & .26 & .61 \\
120 & $\cdot 19$ & .33 & .75 \\
180 & .22 & .35 & .84 \\
\hline
\end{tabular}

(II.) Value of $\mathrm{E}$ on breaking circuit $=1.05$ volt.

\begin{tabular}{|r|r|l|l|}
\hline 5 & less than $\cdot 01$ & .03 & $\cdot 17$ \\
10 & 01 & .04 & $\cdot 25$ \\
20 & $\cdot 02$ & .05 & $\cdot 31$ \\
30 & .03 & .06 & $\cdot 37$ \\
60 & $\cdot 04$ & $\cdot 07$ & $\cdot 44$ \\
120 & $\cdot 06$ & .09 & $\cdot 49$ \\
180 & .07 & $\cdot 10$ & .52 \\
\hline
\end{tabular}

It is evident from these numbers, specimens of many similar experiments, that the predictions from the general theorem mentioned in $\S 69$ are completely verified by experiment. It may be noticed in passing that with the "largest" voltameter, when the value of $E$ on breaking circuit was below 1 volt, the minimum rate of fall of polarization was so slow that no visible motion of the spot of light occurred even during many seconds, and with still lower values of $E$ even after several minutes.

72. The following experiments are also of interest in connexion with this subject, as indicating how the rate of fall of polarization is affected not only by the removal of the auræ of gas round the electrodes by diffusion from one to the other of fluid containing dissolved gas, but also by the solution of the aura in the fluid itself (if not saturated with the gas constituting the aura), and also by the passage of gas into or ont from the interior of the electrode, thus causing a diminution in the aura or vice versâ. Platinum- or gold-foil electrodes of various sizes being arranged in U-shaped voltameters like those just described, a gentle current was passed for some days, so as

Phil. Mag. S. 5. Vol. 11. No. 17. Murch 1881. 'I' 
to saturate as far as possible, not only the liquids surrounding the electrodes with the gases respectively evolved on the electrodes, but also the interior of the foils with occluded gases. The electrodes were then rapidly removed, rinsed with recently boiled just cool acid to remove adherent solution of hydrogen or oxygen, and dipped into a U-tube containing the same recently boiled just cool acid. On connecting the two pieces of foil with a quadrant-electrometer a considerable potential difference was at once indicated. The two pieces of foil were then connected by a shortcircuiting wire for a short time (ten seconds usually); on removal of the wire, the foils being still connected with the electrometer, the spot of light moved regularly for a considerable time, indicating a gradual increase in the E.M.F. of the voltaic arrangement thus produced, from 0 at the moment of removal of the shortcircuiting wire up to a maximum, which was maintained for some time, after which the E.M.F. gradually fell, precisely as in the experiments just described. It is evident that this development and rise of the E.M.F. set up was due to the formation and increase of an aura of gas round each electrode, the source of which was clearly the gas occluded internally in each respectively, the which gas now passed outwards by a reversal of the process by which it formerly passed inwards. The following three sets of readings (averages of fairly concordant repetitions of each experiment) will serve as specimens of a large number of analogous results; the numbers show the E.M.F. set up after the annexed time had elapsed :-

\begin{tabular}{|c|c|c|c|}
\hline Voltameter used...$\ldots \ldots \ldots \ldots \ldots \ldots$ & " Largest." & "Largest." & "Medium." \\
\hline 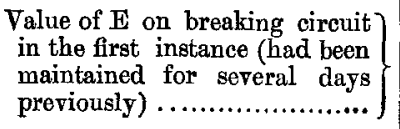 & $1 \cdot 05$ volt. & 1.95 volt. & $2 \cdot 20$ volts. \\
\hline 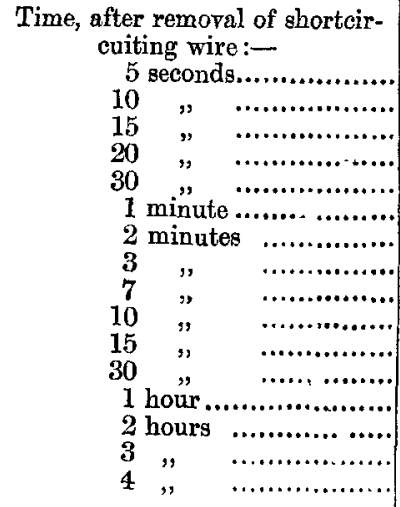 & $\begin{array}{l}\text { volt. } \\
\cdot \mathbf{1 4} \\
\cdot 19 \\
\cdot 21 \\
\cdot 23 \\
\cdot 25 \\
\cdot 27 \\
\cdot 28 \\
\cdot 29 \\
\cdot 29 \\
\cdot 28 \\
\cdot 28 \\
\cdot 27 \\
\cdot 26 \\
\cdot 245 \\
\cdot 235 \\
\cdot 23\end{array}$ & $\begin{array}{r}\text { volt. } \\
\cdot 35 \\
\cdot 41 \\
\cdot 43 \\
\cdot 45 \\
\cdot 47 \\
.52 \\
.55 \\
.57 \\
.59 \\
.59 \\
.57 \\
.53 \\
.49 \\
.44 \\
.42 \\
\cdot 40\end{array}$ & $\begin{array}{c}\text { volt. } \\
\cdot 39 \\
\cdot 44 \\
\cdot 47 \\
.50 \\
.52 \\
.55 \\
.58 \\
.59 \\
.60 \\
.58 \\
.55 \\
.50 \\
.34 \\
.31 \\
.29 \\
.28\end{array}$ \\
\hline
\end{tabular}


In these three cases the maximum E.M.F. was attained respectively after about $3-7,7-10$, and 7 minutes. The value of the maximum was much higher in the secoud case than in the first, indicating a much greater amount of gas occluded, as might be anticipated, since a much more rapid current flowed during the period before the electrodes were disconnected from the battery, the current being near to 000001 and 000020 weber during these periods in the first and second cases respectively. Notwithstanding, however, that a still more rapid current (about 000025 ) Howed in the third case, the maximum attained was scarcely higher than that in the second, because the smaller surface of the electrode caused the rate of loss of aura by solution in the unsaturated surrounding fluid and diffusion away of the solution thus formed to another part of the U-tube to be relatively larger in this case; consequently the rate of fall after the maximum had been reached was considerably more rapid.

73. A curious effect is sometimes produced by the gradual passage outwards from electrodes of occluded gases and the formation of an aura round each, thus virtually setting up a kind of Grove's gas battery. If the current passing through a voltameter be suddenly largely diminished (but not altogether interrupted) by diminishing the E.M.F. of the battery used, a considerable decrease is brought about in the counter E.M.F. set up in the voltameter; that is, the value of $e=\mathrm{E}_{1}+[\Sigma\{(1-n) \mathrm{H}\}-\Sigma(n h)-\Sigma(\mathrm{H})] \chi \mathrm{J}$ diminishes. The passage outwards of occluded gas from the interior of the electrodes, however, tends to increase the aura round each electrode, and consequently to diminish $\Sigma(n h)$, and hence to increase $e$; and the result is that the voltameter behaves for a while like a more powerful opposed battery; so that the current for a time passes in the opposite direction to that due to the primary elec-. tromotor: of course this effect can only be produced when the E.M.F. of the primary electromotor (after the reduction in its E.M.F.) does not exceed some particular limit. If the experiment be modified by shortcircuiting the electrodes of the voltameter before again coupling them to the battery after reducing its E.M.F., the current will at first pass in the normal direction due to the battery; but as the occluded gases pass outwards from the interior of the electrodes and so form an aura round each, the current passing gradually diminishes in strength until it becomes nil, and finally passes in the opposite direction, just as it would have done at first had the voltameter not been shortcircuited. For example, a current of about $\cdot 00005$ weber (capable of evolving about 0.5 cubic centim. of hydrogen per day) was passed for several days through 
a voltameter till the liquids surrounding the electrodes were saturated with oxygen and hydrogen respectively, for which purpose a battery of two Minotiti cells was used. One Minotti cell was then excluded from the circuit, a resistance of 50,000 ohms being included therein (the current being measured by determining the difference of potential set up between the ends of this resistance, as described in $\$ 69)$, and the voltameterplates shortcircuited for a few seconds. After removing the shortcircuiting wire, the current passed at a rapidly slackening rate in the direction due to the Minotti cell; but in a very few minutes it ceased to flow altogether, and then began to flow in the opposite direction. The shortcircuiting of the voltameter-plates was then repeated for two minutes, after which the current flowed in the normal direction at a gradually slackening rate: after one hour the current still flowed in the normal direction and had a value of +0.0000034 weber; but soon it became reduced to zero again, and then flowed in the reverse direction, having a valne of -0.0000017 weber after two hours had elapsed since the second shortcircuiting. After twenty hours more the current was so small that its direction was inappreciable; but on removing the electrodes and igniting them and then replacing them, it flowed continuously in the normal direction. Similar results were obtained in many other analogous experiments.

The gradual setting-up again of an E.M.F. after shortcircuiting the electrodes of a voltameter has been already previously noticed by Ayrton and Perry, and the effect generally compared by them to the residual charge of a Leyden jar; they do not, however, appear to have observed the gradual extinction and reversal of the current just described.

74. It should further result from the general theory of elec- trolysis above stated, that if the electrodes of a voltameter are shortcircuited whilst still in contact with the fluid saturated with gases surrounding them, on removing the shortcircuiting wire the reproduction of an aura round each electrode will take place much more rapidly than will be the case were the electrodes removed and placed in fresh acid not saturated with gas, as in the experiments described in $\$ 72$; for in the former case the loss of aura produced by the passage outwards of occluded gas owing to solution in the liquid will be much smaller than that taking place in the latter case. That this is so the following numbers show, samples of numerous similar observations made, each series of numbers being the average of several fairly accordant sets of determinations.

(I.) Platinum electrodes, exposing a surface of $27 \cdot 4$ square centims. each, kept at a difference of potential of 1.95 volt in 
each case for several days before the observations were made, the current passing being near to $\cdot 00002$ weber. Shortcircuited for ten seconds.

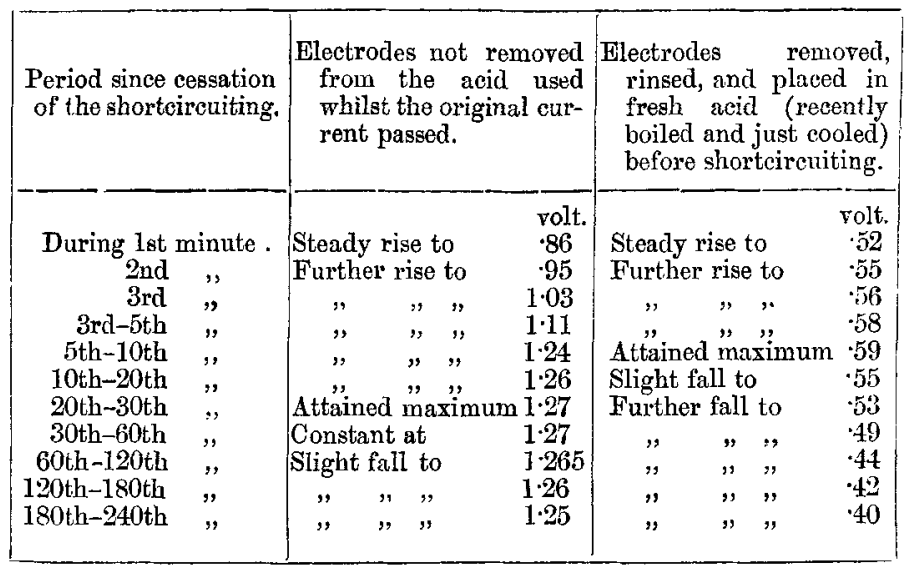

(II.) Electrodes exposing a surface of $3 \cdot 2$ square centims. each, kept at potential-difference of $2 \cdot 20$ volts, the current being near $\cdot 000025$ weber. Shortcircuited for ten seconds.

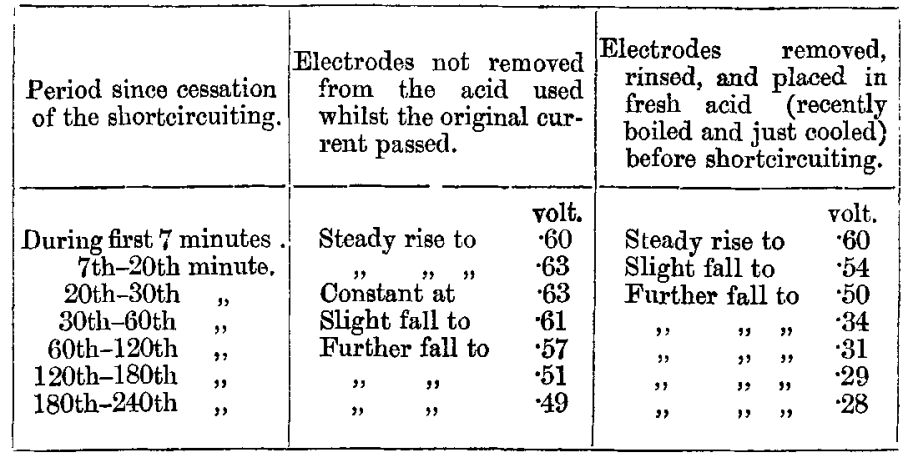

75. The absolute mass of gas occluded by even moderately large foil electrodes is but minute ; on Sprengelpumping at a red heat a platinum-foil electrode of about 160 square centims. total surface (about 16 centims. long, and 5 broad), weighing four grammes, only barely recognizable traces of hydrogen were obtained, even when the electrode had been used for a long time and hydrogen copiously evolved from its surface during electrolysis. The presence of occluded hydrogen, however, can readily be observed by chemical tests 
such as the reduction of ferric to ferrous salts, \&c. One of the most sensitive was found to be that used by Osann (Pogg. Ann. xcv. pp. 311 and 315), viz. washing the electrode (in recently boiled just cool distilled water), and then immersing it in a clear brown-yellow solution of mixed ferric chloride and potassium ferricyanide. In a few minutes, according to the quantity of hydrogen occluded, a distinct blue precipitate forms on the surface of the platinum, due either to the conversion of ferri- into ferrocyanide, or to the reduction of ferric to ferrous chloride, or both together. In this way the presence of hydrogen can be distinguished in a platinum electrode (ignited in oxygen previously to use in the voltameter), even when no visible evolution of hydrogen gas from its surface has occurred, the E.M.F. of the battery used being too small to admit of a steady current passing at a rate more rapid than that representing the rate at which removal of the aura of condensed gas by the effects of diffusion $(\$ 70)$ takes place-for instance, when the battery-E.M.F. is not greater than 1.4 to 1.5 volt (Part iv. $\$ 84$ et seq.). In applying this test, however, too much reliance must not be placed on the formation of a blue precipitate after the lapse of a long time; for organic matters and reducing gases and vapours from the air are apt to be absorbed by the ferric ferrocyanide liquor, causing reduction, especially under the influence of light. Moreover even platinum recently ignited and cooled in oxygen, when placed in the solution, becomes covered with a thin blue film after a considerable time (some hours or days), suggesting the possible reduction of ferricyanide to ferrocyanide with simultaneous production of platinocyanide. Gold acts in this way much more rapidly than platinum. In applying this test in the above-cited observations, check experiments were always made with a second piece of platinum foil of about the same size recently ignited: the blue deposit on the foil used as electrode was then found to be notable or considerable when none at all was visible on the check piece.

76. From the general theory of electrolysis and the experiments above described, and the much more numerous analogous observations made but not described in detail for the sake of saving space, it results that the condition of the aura round each electrode of a voltameter that has been used for decomposing water at a given period since rupturing the original current is influenced by many circumstances. The aura round the - electrode, for example, has a particular mean density at the moment of breaking circuit, whilst that round the + electrode has some other mean density, the 
polarization then existent being governed by the proportions of " nascent" hydrogen and oxygen that were being evolved the instant previously and the mean densities of the aura, $i . e$. by the values of $n_{1}$ and $n_{2}$ and $h_{1}$ and $h_{2}$ in the expression

$$
e=\mathrm{E}_{1}+\left\{\left(1-n_{1}\right) \mathrm{H}_{1}-n_{1} h_{1}+\left(1-n_{2}\right) \mathrm{H}_{2}-n_{2} h_{2}-\Sigma(\mathbf{H})\right\} \chi \mathbf{J}
$$

( $\S 61)$. After the lapse of a given time, however, more or less of the "nascent" hydrogen and oxygen have rearranged themselves, and more or less of the original aura round each electrode has become reconverted into water by the effects of diffusion (bringing oxygen-containing fluid to the hydrogenelectrode and vice vers $\hat{a}$ ); so that from these causes $n_{1}$ and $n_{2}$ have increased, each of these changes diminishing the value of $e$, the polarization. Simultaneously, however, each aura has been more or less reinforced by the passage outwards of occluded gas from within, each of these changes tending to increase $e$. Presumably the greater the extent to which the aura was wasted, so to speak, by diffusion, the more rapidly would this outward passage of occluded gases take place; so that finally the rate of fall of polarization is gradually retarded, first because as the "nascent" hydrogen and oxygen become expended by spontaneous rearrangement this source of fall of polarization regularly diminishes, and secondly because the greater the fall the more energetic is the restoring influence of the outward passage of the occluded gases, at least until the amount occluded becomes materially reduced in quantity. When the amount of fall is such that the rate of outward passage of occluded gases almost balances the rate of wasting of aura through diffusion, the rate of fall of polarization becomes almost insensible, at any rate for periods of time not too prolonged. This point was reached in many of the experiments, in particular those with the "largest" voltameter and polarizations of values not exceeding a few tenths of a volt $(\$ 71)$. Ultimately, however, the occluded gases become exhausted and the auræ diminish to inappreciable quantities, the value of $e$ diminishing to a quantity too small to measure. This result requires an enormous length of time to bring it about by the action of diffusion only; if, however, the voltameter-plates are united by an external connecting-wire, a current flows through that wire, and work is done at the expense of the energy stored up, so to speak, in the auræ and occluded gases of the electrodes. The capacity of the condenser virtually formed by the voltameter-plates simply means the quantity of electricity that can be made to flow in this way, and will approach the more nearly to the quantity of electricity that passed in forming the auræ and charging the 


\section{Lord Rayleigh on Copying Diffraction-gratings,}

electrodes with occluded gases the less has been the waste of auræ by diffusion \&c. During the passage of the current, the aurx and the occluded gases are used up by chemical action, just as the zinc is in an ordinary cell; and as their quantity diminishes, the effective E.M.F. of the voltaic couple formed by the plates also diminishes.

If through leakage of the apparatus, or other causes, atmospheric air obtains access to the liquid surrounding the - electrode, the dissolved oxygen thence resulting will of course tend to reduce the aura of hydrogen by a chemical action of a kind akin to the "local action" of an ordinary voltaic element, i. e. not contributing to the work done by the current generated. In this case the rate of fall of the "subsequent polarization " (the electrode not being connected by a wire so as to produce a current) will be more or less enhanced above the rate due to diffusion only, as above described $(\$ 70)$; whilst if the electrodes are connected and a current is made to pass, the E.M.F. of the voltaic couple thus produced will diminish more rapidly than would be the case were no dissolved oxygen present in the liquid round the hydrogenplate, just as the zinc of an ordinary cell wastes more rapidly when there is local action than it does when there is not, other things being equal.

XXV. On Copying Diffraction-gratings, and on some Phenomena connnected therewith. By LORD RAYLEIGH, F.R.S., Professor of Experimental Physics in the University of Cambridge.*

TN the Phil. Mag. for February and March 1874 I gave an 1 account of experiments in the photographic reproduction of gratings ruled with lines at a rate of 3000 and 6000 to the inch. Since that time I have had further experience, extending to more closely ruled gratings, and have examined more minutely certain points which I was then obliged to leave unexplained. The present communication is thus to be regarded as supplementary to the former.

Some years ngo Prof. Quincke described an unphotographic process by which he had succeeded in copying engraved glass gratings. He began by depositing a thin coating of silver by the chemical method upon the face of the grating. The conducting layer thus obtained was then transferred to an electrolytic cell, and thickened by the deposit of copper, until stout enough to be detached from the glass substratum. In this way he prepared an accurate cast of the * Communicated by the Author. 